\title{
Hydrophobic Coatings on Cotton Obtained by In Situ Plasma Polymerization of a Fluorinated
}

\section{Monomer in Ethanol Solutions}

Ricardo Molina ${ }^{1 *}$, Josep Maria Teixidó ${ }^{1}$, Chi-Wai Kan ${ }^{2}$, Petar Jovančic ${ }^{1,3}$

1 Institute of Advanced Chemistry of Catalonia (IQAC), Department of Chemical and Surfactants Technology, Plasma Chemistry Group, Consejo Superior de Investigaciones Cientificas (CSIC), Barcelona 08034, Spain

${ }^{2}$ Institute of Textiles and Clothing, The Hong Kong Polytechnic University, Hung Hom, Kowloon, Hong Kong

${ }^{3}$ Faculty of Technology and Metallurgy, Textile Engineering Department, University of Belgrade, Belgrade 11120, Serbia

*Corresponding author

Dr. Molina is to be contacted at Tel.: +34 934006100 ext. 2304; fax: +34 932045904 .

E-mail address: ricardo.molina@iqac.csic.es 
Abstract: Plasma polymerization using hydrophobic monomers in the gas phase is a well known technology in order to generate hydrophobic coatings. However, synthesis of functional hydrophobic coatings using plasma technology in liquids has not yet been accomplished. This work is consequently focused on polymerization of a liquid fluorinated monomer on cotton fabric initiated by atmospheric plasma in dielectric barrier discharge configuration. Functional hydrophobic coatings on cotton were successfully achieved using in situ atmospheric plasma initiated polymerization of fluorinated monomer dissolved in ethanol. Gravimetric measurements reveals that the amount of polymer deposited on cotton substrates can be modulated with the concentration of monomer in ethanol solution and crosslinking reactions occur during plasma polymerization of fluorinated monomer even without the presence of a crosslinking agent. FTIR and XPS analysis were used in order to study the chemical composition of hydrophobic coatings and to get insights into the physicochemical processes involved in plasma treatment. SEM analysis reveals that at high monomer concentration, coatings posses a three dimensional pattern with a characteristic interconnected porous network structure. EDX analysis reveals that plasma polymerization of fluorinated monomers takes place preferentially at the surface of cotton fabric and negligible polymerization takes place inside cotton fabric. Wetting time measurements confirm the hydrophobycity of cotton coatings obtained although equilibrium moisture content was slightly decreased. Additionally, the abrasion behavior and resistance to washing of plasma coated cotton has been evaluated.

Keywords: Plasma in liquids; fluorinated monomer; plasma polymerization; cotton; hydrophobic coatings; abrasion. 


\section{INTRODUCTION}

Plasma polymerization is a well described approach for thin deposition of coatings over a huge variety of materials. ${ }^{1}$ It is widely known that surface properties of polymeric materials are not always suitable for targeted application despite adequate bulk properties. By modifying just its surface chemistry and/or morphological structure or by designing proper coatings, it is possible to modulate interfacial properties of polymer materials. The great advantage of plasma is that it is possible to modify these interfacial properties without affecting the bulk properties. ${ }^{2}$ Various surface characteristics such as wettability, adhesion and biocompatibility can be adequately modified by plasma for application in a variety of industrial areas like automotive, microelectronics and biomedicine. ${ }^{3-5}$ Nevertheless, materials obtained from plasma polymerization can be characterized as completely new materials with properties that are different from those obtained by conventional polymerization processes. In contrast to conventional chemical (radical transfer) or physical (such as photoinduced) polymerization reactions, plasma polymerization is a complex process where both chemical and physical processes can take place concurrently. Chemical processes are mainly attributed to active molecules present in the plasma, such as free radicals and electrons, whereas physical processes are attributed to UV-visible emissions that originate from active molecules present in the plasma or to molecule/electron bombardment. These processes are responsible for fragmentation and random rearrangement of atoms during the reaction, leading generally to the formation of amorphous polymer structures. ${ }^{6-7}$

Plasma, a partially ionized gas generated by an electrical discharge, consists of neutral particles (molecules, excited atoms, free radicals and metastable particles), charged particles 
(electrons and ions) and electromagnetic radiation resulting from atomic/molecular deexcitation. Plasma can be generally classified in equilibrium (thermal) and nonequilibrium (nonthermal) plasmas. Non-equilibrium plasmas can keep gas molecules and ions "cold" (close to room temperature), while electrons can be made very "hot" (thousands of degrees C). These high energy electrons are responsible for initiating chemical reactions in gas phase, by breaking covalent chemical bonds of ground state gas molecules in the course of the collision induced energy transfer. Non-thermal plasma can be generated in low and atmospheric pressure conditions. While low pressure plasma is a known technology, atmospheric pressure plasma discharges have evoked growing interest since continuous processes can be performed and no vacuum systems are involved, allowing plasma treatment of materials that are not compatible with vacuum pressure. Particularly, atmospheric pressure plasma discharged in liquid and/or in contact with liquids has enormous significance because at low plasma energy doses the monomer structure and functionality remains almost intact during the treatment. ${ }^{8-9}$ Discharges in liquids and in contact with liquids generate intense UV radiation, shock waves and reactive species (e.g. $\mathrm{OH}$, atomic oxygen, hydrogen peroxide). Atmospheric plasmas discharge in contact with liquids are applied in different fields, such as degradation of organic pollutants, ${ }^{10-11}$ bio-decontamination or sterilization, ${ }^{12-14}$ surface material modification, ${ }^{15}$ dermatology, ${ }^{16}$ wound healing, ${ }^{17}$ tissue engineering and biomedicine in general. ${ }^{18}$

As mentioned previously, the use of low pressure plasma technology for treatment of textiles as a surface modification technique has been successful. ${ }^{8,}{ }^{19}$ Accordingly, it is possible to increase the hydrophilicity (using oxidizing gases), incorporate new chemical groups, deposit functional thin films (using reactive and polymerizing gases) or confer hydrophobicity (using 
fluorinated or siloxane gases) over the textile/polymeric materials. ${ }^{20-21}$ Different methods using plasma technology have been applied in order to impart hydrophobic properties to textiles. One of these methods involves plasma grafting of hydrophobic groups on polymer/textile surface or immersion in a fluid containing the hydrophobic prepolymer. ${ }^{8}$ Several research groups have investigated enhancement of hydrophobicity of fabrics and polymers using plasmas containing volatile low molecular mass hydrophobic precursors $\mathrm{CF}_{4}, \mathrm{C}_{2} \mathrm{~F}_{6}, \mathrm{C}_{3} \mathrm{HF}_{7}, \mathrm{C}_{2} \mathrm{H}_{2} \mathrm{~F}_{4}, \mathrm{C}_{3} \mathrm{~F}_{8}{ }^{22-23} \mathrm{C}_{3} \mathrm{~F}_{6}{ }^{24}$ and $\mathrm{C}_{4} \mathrm{~F}_{8} \cdot{ }^{25-26}$ Recently, hydrophobic coatings have been polymerized in low pressure plasmas using precursors containing unsaturated carbon-carbon bonds with perfluoroalkyl side chains such as $1 \mathrm{H}, 1 \mathrm{H}, 2 \mathrm{H}, 2 \mathrm{H}$-perfluorodecyl acrylate $;{ }^{27-28} 1 \mathrm{H}, 1 \mathrm{H}, 2 \mathrm{H}, 2 \mathrm{H}$-perfluooctyl acrylate; ${ }^{29}$ and $1 \mathrm{H}, 1 \mathrm{H}, 2 \mathrm{H}, 2 \mathrm{H}$-perfluoro-1-dodecene. ${ }^{30-31}$ In our previous work, hydrophilic-oleophobic coatings were deposited on cellulosic materials by means of in situ plasma polymerization of acrylic acid aqueous solutions followed by a cationic fluorosurfactant complexation. ${ }^{32}$ Novel possibilities for creating functional thermo-responsive poly ( $\mathrm{N}$-isopropyl acrylamide) (pNIPAAm) coatings, ${ }^{33-34}$ as well as gelation of chitosan ${ }^{35}$ based on atmospheric pressure plasma dielectric barrier discharges (DBDs) in contact with liquids have also been recently reported.

Whereas in plasma polymerization using monomers in the gas phase thickness coating can be modulated by the plasma treatment time, ${ }^{22-31}$ in plasma initiated polymerization in liquids thickness coating can be modulated with the concentration of monomer present in the liquid. ${ }^{32}$ The use of liquid plasma technology for functional textile coatings is still an emerging field with considerable potential for diverse applications and significant impact on science and society though there still are unresolved scientific challenges that need to be addressed. However, synthesis of functional hydrophobic coatings using plasma technology in liquids has not yet been 
accomplished. This work is consequently focused on polymerization of a liquid perfluoroalkyl side chain monomer on cotton fabric initiated by a nonthermal atmospheric pressure dielectric barrier discharge plasma. In order to control de amount of monomer deposited on cotton fabrics, different concentrations of monomer in ethanol solution was used.

\section{EXPERIMENTAL SECTION}

\subsection{Materials}

Cotton fabrics (plain weave, bleached without optical brightener with a $180 \mathrm{~g} / \mathrm{m}^{2}$ weight (article 210) from EMPA) were used as substrates. Concentrated detergent for pretreating textiles Tanaterge ${ }^{\circledR}$ Advanced, from Tanatex. 1H, 1H, 2H, 2H - Heptadecafluorodecylmethacrylate (97\%, Sigma Aldrich) was used as fluorinated monomer (FM) for plasma initiated polymerization. Divinylbenzene (80\%, Sigma Aldrich) was used as a crosslinking hydrophobic monomer. Both monomers are in liquid state. Ethanol, absolute was provided by Merck. Cotton was first conditioned by washing of the fabric for 45 minutes at $60^{\circ} \mathrm{C}$, under constant stirring at $250 \mathrm{rpm}$. Washing solution was prepared by using Tanaterge ${ }^{\circledR}$ as detergent at $2 \mathrm{~g} / \mathrm{L}$ concentration and washing was carried out at 1/25 (w/v) load/wash solution ratio. Subsequently, the fabric was rinsed by placing it into distilled water for 20 minutes. Finally, the cotton fabric was dried and stored in a conditioned room at $67 \%$ relative humidity (R.H.) and a temperature of $24^{\circ} \mathrm{C}$.

\subsection{Plasma reactor}

A dielectric barrier discharge (DBD) reactor operating at atmospheric pressure was used in this work (Figure 1). Gas mass flow meter and controllers (Bronkhorst, Ruurlo, Netherlands) were 
used in order to introduce helium gas $\left(5 \mathrm{Ln} \cdot \mathrm{min}^{-1}\right)$ in the reactor chamber. A $16 \mathrm{kHz}$ signal was generated with a GF-855 function generator (Promax, L'Hospitalet de Llobregat, Spain) connected to a linear amplifier AG-1012 (T\&C Power Conversion Inc., Rochester, NY, USA). The incident power in the plasma reactor was kept constant at $30 \mathrm{~W}$. A matching network and two transformers (HR-Diemen S.A., Sant Hipòlit de Voltregà, Spain) were connected to the amplifier output in order to increase the voltage up to $\approx 20 \mathrm{kV}$. The distance between the two electrodes was kept constant at approximately $12 \mathrm{~mm}$.

\subsection{Plasma initiated polymerization}

Cotton fabrics $(2 \mathrm{~cm} \times 2 \mathrm{~cm})$ were introduced into the plasma reactor and $100 \mu$ l of different fluorinated monomer solutions in ethanol (between 0.2 and $100 \mathrm{wt} \%$ ) were placed over the substrates. Ethanol was used as a solvent in order to control the initial amount of liquid monomer deposited on the cotton fabrics and additionally to guarantee a homogeneous distribution of the liquid monomer. Copolymerization with hydrophobic divinylbenzene (liquid crosslinking agent) at different concentrations $(1 \%, 5 \%$ and $10 \%)$ was performed for samples treated with $10 \%$ of fluorinated monomer. The plasma initiated polymerization reaction was performed at least in duplicates for a total time of 15 minutes at $30 \mathrm{~W}$.

\subsection{Characterization of cotton substrates coated with fluorinated polymer}

\subsubsection{Amount of polymer deposited on cotton substrates}

The amount of monomer that has been polymerized on cotton fabrics was determined by gravimetric method. In this way, the amount of polymer deposited $\left(\mathrm{W}_{\text {coating }}\right)$ on cotton has been calculated taking into account that the change in weight of the dry treated samples $\left(\mathrm{W}_{\mathrm{dry}}\right)$ respect 
to the initial weight of each fabric $\left(\mathrm{W}_{\mathrm{o}}\right)$ corresponds to the change in weight as a consequence of the deposited polymer layer and the elimination of the initial absorbed water $\left(\mathrm{W}_{\mathrm{H} 2 \mathrm{O}}\right)$ (equation 1). Therefore, before each plasma treatment, initial weight of conditioned untreated fabric was determined $\left(\mathrm{W}_{\mathrm{o}}\right)$. After plasma treatment, cotton substrates were dried in an drying oven (APT.line FD (E2), Binder Gmbh) at $105^{\circ}$ during 24 hours in order to eliminate the absorbed water and the weight of the dried samples, corresponding to the sum of the polymer coating and the dried cotton weight, was determined $\left(\mathrm{W}_{\mathrm{dry}}\right)$. The amount of water absorbed in untreated cotton fabrics $\left(\mathrm{W}_{\mathrm{H} 2 \mathrm{O}}\right)$, conditioned at constant humidity (67\% R.H.) and temperature $\left(24^{\circ} \mathrm{C}\right)$, was also determined. For this porpoise, untreated conditioned cotton fabrics were dried in an oven at $105^{\circ} \mathrm{C}$ during 24 hours in order to eliminate the absorbed water. The amount of water absorbed has been determined by equation 2 . Untreated cotton fabrics display an average of $6.45 \pm 0.03 \%$ of absorbed water at the experimental ambient conditions used.

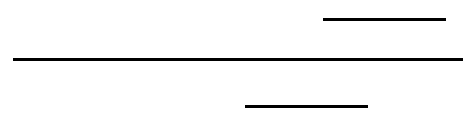

\subsubsection{Amount of crosslinked polymer deposited on cotton substrates}

The crosslinking efficiency CE (\%) was indirectly calculated from the soluble fraction in ethanol of the unreacted and linear polymerized monomer that are present in the coated cotton fabrics after plasma treatment. For this purpose, plasma coated cotton substrates were immersed in 
ethanol for at least 24 hours and subsequently dried 24 hours at $105^{\circ} \mathrm{C}$. CE (\%) was calculated according to the equation (3):

$$
\mathrm{CE}(\%)=\left(\mathrm{W}_{\mathrm{EtOH}} / \mathrm{W}_{\text {coating }}\right) \times 100
$$

where $\mathrm{W}_{\mathrm{EtOH}}$ is the amount of polymer that remains deposited after immersion in ethanol for at least $24 \mathrm{~h}$ and $\mathrm{W}_{\text {coating }}$ is the amount of polymer deposited after the plasma treatment.

\subsubsection{Equilibrium moisture of cotton substrates}

In order to determine if the presence of hydrophobic coatings in cotton substrates affects water vapor diffusion into cotton substrates, the equilibrium moisture of cotton fabrics was determined. After plasma treatment, cotton fabrics were conditioned at $67 \%$ relative humidity (R.H.) and a temperature of $24^{\circ} \mathrm{C}$ for at least 24 hours. Equilibrium moisture on cotton fabrics was determined taking into account the weight increase as a consequence of the humidity present in the conditioned room respect to the dry weight of cotton substrate (equation 2).

\subsubsection{Fourier Transformed Infrared (FTIR)}

FTIR spectra of untreated and plasma polymerized cotton fabrics were collected using a Nicolet Avatar 360 spectrometer equipped with a Smart iTR Attenuated Total Reflectance (ATR) Sampling Accessory (Thermo Scientific Inc., U.S.A). Spectra were obtained with an average of 32 scans using a resolution of $4 \mathrm{~cm}^{-1}$. An advanced ATR correction algorithm (OMNIC 7.3 from Thermo Electron Corporation) was used in order to correct for band intensity distortion, peaks shifts and polarization effects. Corrected ATR spectra were found highly comparable to their transmission equivalents. ${ }^{36}$ 


\subsubsection{X-ray Photoelectron Spectroscopy (XPS)}

Surface chemical composition of the coated fabrics was studied by XPS measurements in an ultra-high vacuum chamber with pressure between $5.10^{-9}$ and $2.10^{-8}$, using a PHI Model 5500 Multitechnique System, equipped with a monochromatic Al $\mathrm{K}_{\alpha}$ source operating at $300 \mathrm{~W}$, placed perpendicular to the analyzer axis. The analyzed area was a circle of $0.8 \mathrm{~mm}$ diameter. Survey scans were taken in the range $0-1100 \mathrm{eV}$, with pass energy of $187.5 \mathrm{eV} / \mathrm{step}$. High resolution scans were obtained on the $\mathrm{C}_{1 \mathrm{~s}}, \mathrm{O}_{1 \mathrm{~s}}, \mathrm{~N}_{1 \mathrm{~s}}$ and $\mathrm{F}_{1 \mathrm{~s}}$ photoelectron peaks, with pass energy of $0.1 \mathrm{eV} / \mathrm{step}$. Binding energies were referenced to the $\mathrm{C}_{1 \mathrm{~s}}$ photoelectron peak position for $\mathrm{C}-\mathrm{C}$ and $\mathrm{C}-\mathrm{H}$ species at $285.0 \mathrm{eV}$ or $\mathrm{C}-\mathrm{O}$ species at $286.4 \mathrm{eV}$ for bleached cotton. ${ }^{37}$ Surface composition was estimated after a linear background subtraction from the area of the different photoemission peaks modified by the corresponding sensitivity factors. ${ }^{38}$

\subsubsection{Scanning Electron Microscopy (SEM) and Energy-dispersive X-ray spectroscopy (EDX).}

Surface morphology of the treated fabrics was observed using a Hitachi S-3500N scanning electron microscope, operated at $5 \mathrm{kV}$, after an $\mathrm{Au}$ sputtering using a Quorum Q150RS (thickness coating $\sim 20 \mathrm{~nm}$ ). Energy-dispersive X-ray spectroscopy (EDX) was carried out with a Bruker AXS spectrometer in the same SEM in order to determine qualitatively the elemental composition of plasma coated cotton substrates. The software used for the analysis of the spectra was Quantax 1.6 (Bruker AXS). An acceleration voltage of $5 \mathrm{kV}$ was used in order to avoid sample charge and damaging of cotton substrates during the measurement. EDX were performed in the upper part (vertical) and in a transversal section of cotton fabrics. For the transversal section measurement, cotton substrate was cut with a scalpel and placed in a $45^{\circ}$ sample holder. 


\subsubsection{Hydrophobic properties of plasma coated cotton substrates: Wetting time measurement}

Textile materials have usually a rough surface due to the presence of fibers, yarns and the empty spaces existing between them. In these materials, capillary forces results in spontaneous wicking when contact angle is below $90^{\circ}$. On the other hand the fabric roughness exerts a large influence on contact angles that are greater than $90^{\circ} .{ }^{39}$ Instead of contact angle analysis on textile fabrics, wetting time (time to absorb a liquid drop) is usually a choice in order to qualitative evaluate hydrophilic or hydrophobic properties of textile fabrics. For this reason, wetting time of a water drop $(10 \mu \mathrm{l})$ in cotton fabrics samples was determined.

\subsubsection{Abrasion resistance of plasma coated cotton substrates}

Abrasion resistance of textiles was done on Martindale wear and abrasion tester (Shirley Developments LTD, U.K.). The Martindale apparatus comprises four testing heads. The fabric sample under study slides, under a given pressure, against the abrasive surface according to two simple harmonic movements in the horizontal plane. Abradant Fabric SM25 (Olsen Fund SL, Spain) was used as the abrasive surface. During testing, not additional pressure was applied to cotton substrates. Weight loss (abraded mass) was determined among four specimens at different abrasion testing cycles $\left(1000,3000,5000\right.$ and 10000). ${ }^{40,41}$ 


\section{RESULTS AND DISCUSSION}

Plasma treatment of cotton fabrics impregnated with a small amount $(100 \mu 1)$ of pure fluorinated monomer FM (1H,1H,2H,2H-Heptadecafluorodecylmethacrylate) and/or fluorinated monomer dissolved in ethanol (0.2 to $20 \mathrm{wt} \%$ ) results in the formation of polymeric coatings which were apparently dried after a plasma polymerization time of 15 min. As expected, amount of polymer $\left(\mathrm{W}_{\text {coating}}\right)$ deposited on cotton fabrics increases as a function of monomer concentration (Figure 2a). A subsequent immersion of cotton substrates in ethanol for 24 hours results in a decrease in the amount of polymer deposited that can be attributed to the solubility in ethanol of unreacted and linear polymerized monomer present in the plasma coated cotton fabrics.

Copolymerization of $10 \%$ of fluorinated monomer with hydrophobic divinylbenzene (DVB) at different concentrations $(1 \%, 5 \%$ and $10 \%)$, results in a non linear increase of the amount of polymer deposited on cotton substrates as a function of the total monomer concentration (Figure 2b). A significant increase in the amount of polymer deposited can be observed when copolymerization is carried out at low concentrations of DVB (10\% FM+1\% DVB). These results are in concordance with previous studies carried out in plasma assisted copolymerization of hydrophilic monomer and crosslinking agent in water solutions, where it was observed that the presence of a small amount of crosslinking agent significantly increases polymerization yield. ${ }^{34}$ However, subsequent increase of crosslinking DVB concentration (10\% FM+ 5\% DVB) does not results in a significant increase in the amount of polymer deposited. At higher concentrations of DVB (10\% FM+ 10\% DVB) the amount of polymer deposited tends to decrease. When polymerization is carried out with pure DVB at $20 \%$ concentration, the amount 
of polymer deposited $(7.5 \pm 0.9 \%)$ is reduced compared to the amount of polymer deposited with pure FM $(10.1 \pm 2.5 \%)$. This result is attributed to the volatility of DVB monomer and consequently the evaporation of DVB monomer prevails over its polymerization in liquid phase. Rinsing of plasma copolymerized substrates in ethanol for 24 hours results in a decrease in the amount of polymer deposited due to the solubility of unreacted and linear polymerized monomer in ethanol. However it can be observed that with an increase in DVB monomer concentration the amount of polymer that is not soluble in ethanol increases due to crosslinking reactions between DVB and FM monomers. Table 1 summarizes total amount of polymer deposited and corresponding percentage of crosslinking polymer present in the plasma polymerized coatings. It can be observed that crosslinking reactions occur even without the presence of a crosslinking agent (DVB). Similar behavior have been found in plasma polymerization of hydrophilic monomers in water solutions. ${ }^{34}$ It is suggested, that high energy reactive species as well as UV radiation present in the plasma gas, could promote additional reactive sites during the polymerization that would lead to crosslinking reactions between linear polymer chains.

Analysis of chemical groups present in plasma polymerized coatings on cotton substrates were analyzed by means of FTIR-ATR and XPS. Figure 3 shows the FTIR-ATR spectra of cotton fabrics coated with plasma initiated polymerization of fluorinated monomer solutions in ethanol at different concentrations $(0.2-100 \mathrm{wt} \%)$ on both sides of the fabric (the front of the fabric which was directly exposed to the plasma and the back of the fabric closer to the inner electrode). 
It can be observed that with an increase in concentration of fluorinated monomer, characteristic bands of bleached cotton corresponding to $\mathrm{OH}\left(1200-1336 \mathrm{~cm}^{-1}\right)$ and C-O $\left(1000-1030 \mathrm{~cm}^{-1}\right)$ decrease whereas characteristic bands of fluorinated polymerized monomer corresponding to $\mathrm{CF}_{\mathrm{x}}$ (1149, 1205 and $\left.1245 \mathrm{~cm}^{-1}\right)$ and $\mathrm{C}=\mathrm{O}\left(1731 \mathrm{~cm}^{-1}\right)$ increase. Since FTIR-ATR analysis is sensitive to detection of chemical functional groups present at microscopic level below a surface $(\approx 1-2 \mu \mathrm{m})$, by increasing the thickness of the deposited layer on cotton substrate, the chemical groups corresponding to cotton substrates would decrease its intensity. Additionally, such as chemical groups corresponding to cotton substrates can be observed in the FTIR-ATR spectra, it is suggested that the thickness of the polymer coating should be lower than $\approx 1-2 \mu \mathrm{m}$. On the other hand, the characteristic vinyl peak $\left(1635 \mathrm{~cm}^{-1}\right)$ corresponding to the non-reacted fluorinated monomer is scarcely observed, suggesting that the polymerization process was almost completed. Interestingly, the same effect was observed on the back of the fabric indicating the DBD atmospheric plasma discharge affected both sides simultaneously. It is suggested that polymerization on the back side of the fabric could be attributed to radical transfer propagation in the liquid and/or to the active species (e.g. free radicals) present in the plasma sheath that surrounds all the fabric. In addition, no new peaks appeared indicating that no formation of new molecular chemical bonds or structures has occurred. Therefore polymerization reactions, during the plasma initiated polymerization of fluorinated monomer in ethanol solutions, seems to prevail over other possible chemical reactions (e.g. oxidation).

While the infrared spectroscopy in ATR mode is sensitive to detection of the chemical functional groups present at microscopic scale, XPS is sensitive to the upper 10 to $30 \mathrm{~nm}$ of a material surface. In this region plasma active species (e.g. oxygen, nitrogen, hydroxyl groups, 
and hydrogen) are in intimate contact with fluorinated monomer solution or the fluorinated polymer during its formation. Therefore, possible surface chemical modifications such as functionalization or degradation have been additionally studied by XPS. Atomic chemical composition corresponding to untreated cotton and plasma initiated polymerized cotton coatings are shown in Table 2. Significant changes in the atomic chemical composition are detected in comparison with untreated cotton as the carbon and oxygen decreased whereas the fluorine content increased significantly. Nevertheless, higher carbon and lower fluorine values are observed after plasma initiated polymerization which respect to the theoretical composition according to the fluorinated monomer structure. Also, no significant changes in oxygen content are observed compared to the atomic composition of fluorinated monomer. These results suggest that during plasma treatment not only polymerization processes occur but also other reactions where ethanol could be involved occur.

Consequently, high-resolution spectra corresponding to carbon functionalities were also studied to get additional insights into the polymerization process. Figure 4 shows the highresolution spectra of $\mathrm{C}_{1 \mathrm{~s}}$ corresponding to untreated cotton and fluorinated cotton coatings obtained by DBD plasma initiated polymerization. Cotton shows a major peak corresponding to C-O functionalities $(286.6 \mathrm{eV})$ and a shoulder band at lower binding energies attributed to aliphatic carbon atoms $(285 \mathrm{eV})$ as expected for a cellulosic fibre. High-resolution spectra corresponding to DBD plasma fluorinated cotton coatings plasma reveal clearly the presence of fluorinated $\left(\mathrm{CF}_{2}\right.$ and $\left.\mathrm{CF}_{3}\right)$ and carbonyl $(\mathrm{C}=\mathrm{O})$ species. However, spectrum corresponding to plasma initiated polymerization of a fluorinated monomer is significantly different from that found previously for a plasma initiated polymerization in vapour phase of the same monomer. ${ }^{27}$ 
In plasma initiated polymerization of fluorinated monomer in ethanol solution, aliphatic carbon atoms predominate over fluorinated carbon atoms (Table 2), suggesting that additional carbon atoms have been introduced on the surface during plasma treatment. This additional carbon atoms represent an indication that ethanol can suffer some reactions or even concurrent polymerization during DBD atmospheric plasma pressure treatment of fluorinated monomer solution.

Morphology of plasma coated fabrics was examined by SEM. In Figure 5, high-resolution SEM images of untreated cotton, cotton previously impregnated with ethanol (EtOH) and subsequently treated by DBD plasma during 15 minutes and cotton coatings obtained after plasma using different concentrations of fluorinated monomer are displayed. Typical longitudinal fibril architecture can be easily observed in untreated cotton (Figure 5 (a)) that is also similar to cotton treated with EtOH (Figure 5 (b).

We have previously indicated (see Table 1) that the amount of deposited polymer increases as a function of fluorinated monomer concentration. Similarly, at low monomer concentration $(0.2 \% \mathrm{FM})$ structure alterations are hardly observed though a very thin layer is deposited (Figure 5 (c)). By increasing the monomer concentration $(2 \% \mathrm{FM})$ a thin coating seems to be completely formed over the cotton fabric (Figure 5 (d)). Finally, an increase in FM concentration from 20\% to $100 \%$ resulted in thicker and microscopically defined rough coating that resembles a three dimensional pattern with characteristic interconnected porous network structure (Figure 5 (e) and Figure 5 (f)). This type of structure is very similar to that obtained in previous studies carried out in plasma assisted copolymerization of hydrophilic monomer in aqueous solutions. ${ }^{33}$ In addition, 
the clear evidence of the fluorinated cotton coatings on the back of the fabric additionally confirms the results of FTIR analysis (see Figure 3).

Since fluorinated monomer and linear polymerized monomer are soluble in ethanol, resistance to washing of plasma coated cotton substrates was evaluated by rinsing in ethanol for at least 24 hours. SEM examination (Figure 6) reveals that after rinsing in ethanol, morphology of plasma coated fabrics is similar to those without rinsing. However, it seems that some material has been removed from the plasma polymerized coating on cotton substrate. Material lost observed is in consistence with solubilization of non crosslinked polymer chains in the coatings. Although some material has been removed after rinsing in ethanol, these results suggest that crosslinked polymer present in the plasma polymerized coatings is well adhered to the cotton fibers and possible swelling of polymer chains in ethanol does not result, after ethanol evaporation, in significant changes in the morphology of the plasma coated cotton substrates.

In order to examine where polymerization of fluorinated ethanol solutions in cotton takes place (surface or inside cotton fabric), EDX analysis was performed in the upper part (vertical) and in a transversal section of cotton fabrics (Figure 7). EDX spectrum carried out in the upper part of the cotton fabrics reveals the presence of fluorine, carbon and oxygen which is consistent with the presence of the plasma polymerized coating. However, EDX analysis of a transversal section of cotton fabrics reveals an absence of fluorine inside plasma coated cotton fabric and only peaks corresponding to cellulose (carbon and oxygen) appears. These results suggest that plasma polymerization of fluorinated monomers takes place preferentially at the surface of cotton fabric. 
To verify the quality of hydrophobic coatings obtained after DBD atmospheric plasma pressure polymerization process, wetting time (Table 3) was measured for both sides of cotton fabric (the front size, directly exposed to the plasma and the back of the fabric). A water droplet placed on the surface of untreated cotton fabric sinks completely into the fabric after less than a second, mainly due to capillary forces. However, a different wetting behavior was observed on the front side of plasma treated with pure ethanol solution $(0 \% \mathrm{FM})$ cotton fabric. The formation of a water droplet and non instantaneous sinking is observed, suggesting that ethanol may have partially functionalized or polymerized itself on cotton fabric. Nevertheless, the wetting time on the other side of the fabric is just slightly modified compared to the untreated one.

After the DBD atmospheric plasma polymerization of cotton treated with small concentration of fluorinated monomer $(0.2 \%)$, an increase in hydrophobicity is observed on the directly plasma exposed side of the fabric, whereas the other side of the fabric has a wetting time similar to the back side of the fabric treated exclusively with ethanol. These results indicate that polymerization at low concentration of fluorinated monomer solutions prevails on the upper side of the fabric, which was directly exposed to the plasma treatment. However, at higher monomer concentrations $(2 \%, 20 \%$ and $100 \%)$, the wetting time is significantly increased regardless of the fabric side. Wetting properties of hydrophobic coatings remains durable even after rinsing in ethanol solutions. This result is in agreement with the presence, observed by SEM (Figure 6), of the hydrophobic coatings on cotton fabrics after rinsing with ethanol.

Wetting behavior observed in this work (DBD atmospheric plasma polymerization of fluorinated monomer in ethanol solutions) is similar to that found in plasma polymerized 
fluorinated films, using monomers in the gas plasma and low pressure, on cellulose ${ }^{42}$. In fluorinated films obtained at low pressure, a polymer coating thickness of $>70 \mathrm{~nm}$ provides a stable water contact angle $\left(\approx 110^{\circ}\right)$ whereas at lower coating thickness water contact angle decreases as a function of time due to capillary forces. For a thickness of $50 \mathrm{~nm}$ a contact angle of $0^{\circ}$ (wetting time in this work) is achieve at $\approx 55 \mathrm{~min}$ and for a thickness of $27 \mathrm{~nm}$ a wetting time of $\approx 15 \mathrm{~min}$ is observed. Therefore, the wetting time observed in this work $(50 \mathrm{~s})$ at very low fluorinated monomer concentration $(0.2 \% \mathrm{FM})$ suggests that the thickness of fluorinated polymer coating on cotton fabric is in the nanometer scale and therefore is difficult to observe in SEM analysis (Figure 5c).

Additionally, the equilibrium moisture in cotton fabrics was determined (Table 4). It is observed a tendency to decrease equilibrium moisture by increasing fluorinated monomer concentration. Although moisture decrease seems not to be large, the presence of hydrophobic coatings in cotton substrates affects water vapor diffusion into cotton substrates. These results are in agreement with the low moisture diffusivity (two orders of magnitude lower) of plasma polymerized fluorocarbon films $\left(4.72 \times 10^{-11} \mathrm{~m}^{2} / \mathrm{s}\right)^{42}$ compare with cellulose based substrates $\left(5.3 \times 10^{-9} \mathrm{~m}^{2} / \mathrm{s}\right){ }^{43}$

Generally hydrophobic coatings have low durability and adhesion properties. ${ }^{44,45}$ For this reason, abrasion resistance on plasma coated cotton fabrics was evaluated (Figure 8). Whereas untreated cotton has a linear abrasion kinetic, plasma treated cotton fabrics have a concave abrasion kinetic attributed to the presence of the fluorinated coating. Abraded mass for the plasma coated cotton fabrics are significantly higher than the corresponding for the untreated 
one, indicating that the plasma polymerized coatings are susceptible to abrasion (mechanical damage). The presence of the crosslinking agent (DVB) does not improve abrasion resistance of plasma polymerized coatings. However, plasma coated cotton fabrics remains hydrophobic even after 10000 cycles. SEM images evidence that after abrasion test, untreated cotton fabrics (Figure 9a) exhibit significant fiber damage and even some broken fibers can also be found. On the other hand, after the abrasion test in the plasma coated cotton fabrics without the presence of a crosslinking agent (Figure 9b), SEM images reveal that the plasma polymerized coating seems almost to be completely removed but cotton fibers exhibit a low mechanical damage as a consequence of the protecting effect of the coating. However, SEM images of plasma coated cotton fabrics with the presence of a crosslinking agent (Figure 9c) reveal that the plasma polymerized coating still present in the cotton fabric although it have suffer a significant morphology change from rough interconnected structures to flat film.

\section{CONCLUSION}

Fluorinated monomer dissolved in ethanol can be successfully polymerized using atmospheric pressure dielectric barrier discharge while its chemical structure is almost retained during plasma treatment. Crosslinking reactions occur during plasma polymerization of fluorinated monomer even without the presence of a crosslinking agent. Copolymerization with a DVB crosslinking agent increases the amount of polymer deposited on cotton substrates. Plasma polymerization takes place preferentially at the surface of cotton fabric as demonstrated by EDX anlaysis. At high monomer concentration, coatings have a three dimensional pattern with characteristic interconnected porous network structure. The presence of hydrophobic coating slightly decreases equilibrium moisture content of cotton fabrics. Wetting time measurement and resistance to 
washing in ethanol of the plasma coated cotton substrates additionally demonstrates that DBD atmospheric plasma initiated polymerization in liquids can be a promising technique to promote the functional hydrophobic coatings onto textiles and porous substrates.

\section{AUTHOR INFORMATION}

\section{Corresponding author}

*E-mail: ricardo.molina@iqac.csic.es

\section{Notes}

The authors declare no competing financial interest.

\section{ACKNOWLEDGMENTS}

We acknowledge the support of the European Regional Development Funds program (EUFEDER), the Spanish Ministry of Economy and Competitiveness (projects MAT2013-40852-R, MAT2013-42900-P) for financial support and grant from the CSIC/RGC Joint Research Scheme sponsored by the Research Grants Council of Hong Kong and the Spanish National Research Council (Reference No. S-HK007/12). The authors would also like to thank J. Fortuño (Electron Microscopy Service, ICM/CSIC, Barcelona, Spain) for his valuable help in SEM and EDX analysis and Prof. Albert Manich for abrasion test measurements. 


\section{REFERENCES}

(1) Carlsson, C. M.; Johansson, K. S. Surface Modification of Plastics by Plasma Treatment and Plasma Polymerization and its Effect on Adhesion. Surf. Interface Anal. 1993, 20, 441-448.

(2) Olde Riekerink, M. B. Structural and Chemical Modification of Polymer Surfaces by Gas Plasma Etching, Ph.D. Thesis, University of Twente, September 2001.

(3) D’Agostino, R.; Favia, P.; Oehr, C.; Wertheimer, M. R. Low-Temperature Plasma Processing of Materials: Past, Present, and Future. Plasma Process. Polym. 2005, 2, 7-15.

(4) Yasuda, H.; Gazicki, M. Biomedical Applications of Plasma Polymerization and Plasma Treatment of Polymer Surfaces. Biomaterials 1982, 3, 68-77.

(5) Shi, F. F. Recent Advances in Polymer Thin Films Prepared by Plasma Polymerization: Synthesis, Structural Characterization, Properties and Applications. Surf. Coat. Tech. 1996, 82, $1-15$.

(6) Yasuda, H.; Plasma Polymerization; Academic Press Inc. Orlando, 1985.

(7) Friedrich, J. Mechanisms of Plasma Polymerization - Reviewed from a Chemical Point of View. Plasma Process. Polym. 2011, 8, 783-802.

(8) Morent, R.; De Geyter, N.; Verschuren, J.; De Clerck, K.; Kiekens, P.; Leys, C. NonThermal Plasma Treatment of Textiles. Surf. Coat. Technol. 2008, 202, 3427-3449.

(9) Joshi, R. S.; Dieter-Schulze, R.; Meyer-Plath, A.; Wagner, M. H.; Friedrich, J. F. Selective Surface Modification of Polypropylene using Underwater Plasma Technique or Underwater Capillary Discharge. Plasma Process. Polym. 2009, 6, S218-S222. 
(10) Hijosa-Valsero, M.; Molina, R.; Schikora, H.; Müller, M.; Bayona, J. M. Removal of Priority Pollutants from Water by means of Dielectric Barrier Discharge Atmospheric Plasma. $J$. Hard. Mater. 2013, 262, 664-673.

(11) Hijosa-Valsero, M.; Molina, R.; Schikora, H.; Müller, M.; Bayona, J. M. Removal of Cyanide from Water by means of Plasma Discharge Technology. Water Res. 2013, 47, 17011707.

(12) Moreau, M.; Orange, N.; Feuilloley, M. G. J. Non-thermal Plasma Technologies: New Tools for Bio-Decontamination. Biotechnol. Adv. 2008, 26, 610-617.

(13) Morgan, N.; Elsabbagh, M.; Desoky, S.; Garamoon, A. A Deactivation of Yeast by Dielectric Barrier Discharge. Eur. Phys. J. Appl. Phys. 2009, 46, 31001.

(14) Moisan, M.; Barbeau, J.; Moreau, S.; Pelletier, J.; Tabrizian, M.; Yahia, L. Low Temperature Sterilization Using Gas Plasmas: A Review of the Experiments and an Analysis of the Inactivation Mechanisms. Int. J. Pharm. 2001, 226, 1-21.

(15) Starikovskiy, A.; Yang, Y.; Cho, Y. I.; Fridman, A. Non-equilibrium Plasma in Liquid Water: Dynamics of Generation and Quenching. Plasma Sources Sci. Technol. 2011, 20, 024003.

(16) Emmert, S.; Brehmer, F.; Hänßle, H.; Helmke, A.; Mertens, N.; Ahmed, R.; Simon, D.; Wandke, D.; Maus-Friedrichs, W.; Däschlein, G.; Schön, M. P.; Viöl, W. Atmospheric Pressure Plasma in Dermatology: Ulcus Treatment and much more. Clinical Plasma Medicine, 2013, 1, 24-29.

(17) Haertel, B.; Woedtke, T.; Weltmann, K. D.; Lindequist, U. Non-Thermal AtmosphericPressure Plasma Possible Application in Wound Healing. Biomol. Ther. 2014, 22, 477-490. 
(18) Fridman, G.; Friedman, G.; Gutsol, A.; Shekhter, A. B.; Vasilets, V. N.; Fridman, A. Applied Plasma Medicine. Plasma Process. Polym. 2008, 5, 503-533.

(19) Plasma technologies for textiles; Shishoo, R., Ed.; Woodhead Publishing: Cambridge, 2007; 360 pp.

(20) Kwong, C. H.; Ng, S. P.; Kan, C. W.; Molina, R. Parametric Study of CF4-Plasma on the Hydrophobicity of Polyester Synthetic Leather. Fiber Polym. 2013, 14, 1608-1613.

(21) Kwong, C. H.; Ng, S. P.; Kan, C. W.; Molina, R. Inducing Hydrophobic Surface on Polyurethane Synthetic Leather by Atmospheric Pressure Plasma. Fiber Polym. 2014, 15, 15961600.

(22) Vinogradov, I. P.; Lunk, A. Spectroscopic Diagnostics of DBD in Ar/Fluorocarbon Mixtures - Correlation between Plasma Parameters and Properties of Deposited Polymer Films. Plasma Process. Polym. 2005, 2, 201-208.

(23) Vinogradov, I. P.; Lunk A. Structure and Chemical Composition of Polymer Films Deposited in a Dielectric Barrier Discharge (DBD) in Ar/Fluorocarbon Mixtures. Surf. Coat. Technol. 2005, 200, 660-663.

(24) Cuddy, M. F.; Fisher, E. R. Contributions of $\mathrm{CF}$ and $\mathrm{CF}_{2}$ Species to Fluorocarbon Film Composition and Properties for $\mathrm{C}_{\mathrm{x}} \mathrm{F}_{\mathrm{y}}$ Plasma-Enhanced Chemical Vapor Deposition. ACS Appl. Mater. Interfaces 2012, 4, 1733-1741.

(25) Labelle, C. B.; Opila, R.; Kornblit, A. Plasma Deposition of Fluorocarbon Thin Films from c-C4F8 using Pulsed and Continuous RF Excitation. J. Vac. Tech. A. 2005, 23, 190-196. 
(26) Kartrick, K. S.; Basak, S.; Chattopadhyay, S. K.; Gayatri, T. N. Water-Free Plasma Processing and Finishing of Apparel Textiles. In Handbook of Sustainable Apparel Production; Muthu, S.S., Ed.; CRC Press: New York, 2015; pp 3-39.

(27) Coulson, S. R.; Woodward, I. S.; Badyal, J. P. S.; Brewer, S. A.; Willis, C. SuperRepellent Composite Fluoropolymer Surfaces. Chem. Mater. 2000, 104, 8836-8840.

(28) Kumar, V.; Pulpytel, J.; Arefi-Khonsari, F. Fluorocarbon Coatings Via Plasma Enhanced Chemical Vapor Deposition of $1 \mathrm{H}, 1 \mathrm{H}, 2 \mathrm{H}, 2 \mathrm{H}$-perfluoro Acrylate-1, Spectroscopic Characterization by FT-IR and XPS. Plasma Process. Polym. 2010, 7, 939-950.

(29) Teare, D. O. H.; Spanos, C. G.; Ridley, P.; Kinmond, E. J.; Roucoles, V.; Badyal, J. P. S. Pulsed Plasma Deposition of Super-Hydrophobic Nanospheres. Chem. Mater. 2002, 14, 45664571.

(30) Coulson, S. R.; Woodward, I. S.; Badyal, J. P. S.; Brewer, S. A.; Willis, C. Plasma chemical Functionalization of Solid Surfaces with Low Surface Energy Perfluorocarbon Chains. Langmuir 2000, 7, 6287-6293.

(31) Laguardia, L.; Ricci, D.; Vassallo, E.; Cremona, A.; Mesto, E.; Grezzi, F.; Dellera, F. Deposition of Super-Hydrophobic and Oleophobic Fluorocarbon Films in Radio Frequency Glow Discharges. Macromol. Symp. 2007, 247, 295-302.

(32) Molina, R.; Gómez, M.; Kan, C. W.; Bertran, E. Hydrophilic-Oleophobic Coatings on Cellulosic Materials by Plasma Assisted Polymerization in Liquid Phase and Fluorosurfactant Complexation. Cellulose 2014, 21, 729-739. 
(33) Molina, R.; Ligero, C.; Jovancic, P.; Bertran, E. In Situ Polymerization of Aqueous Solutions of NIPAAm Initiated by Atmospheric Plasma Treatment. Plasma Process. Polym. 2013, 10, 506-516.

(34) Jovancic, P.; Vílchez, A.; Molina, R. Synthesis of Thermo-Sensitive Hydrogels from Free Radical Copolymerization of NIPAAm with MBA Initiated by Atmospheric Plasma Treatment. Plasma Process. Polym. 2016, 13, 752-760.

(35) Molina, R.; Jovancic, P.; Vilchez, S.; Tzanov, T.; Solans, C. In Situ Chitosan Gelation Initiated by Atmospheric Plasma Treatment. Carbohyd. Polym. 2014, 10, 472-479.

(36) Molina, R.; Solé, I.; Vílchez, A.; Bertran, E.; Solans, C.; Esquena, J. Surface Functionalization of Macroporous Polymeric Materials by Treatment with Air Low Temperature Plasma. J. Nanosci. Nanotechno. 2013, 13, 2819-2825.

(37) Gorjanc, M.; Bukosek, V.; Gorensek, M.; Mozetic, M. $\mathrm{CF}_{4}$ Plasma and Silver Functionalized Cotton. Text. Res. J. 2010, 80, 2204-2213.

(38) Practical Surface Analysis by Auger and X-ray Photoelectron Spectroscopy; Briggs, D., Seah, M. P., Eds.; John Wiley and Sons Ltd: Chichester, 1983; 533 pp.

(39) Molina, R.; Esquena, J.; Erra, P. Interfacial Processes in Textile Materials: Relevance to Adhesion. J. Adhesion Sci. Technol. 2010, 24, 7-33.

(40) Miguel, R.; Lucas, J.; Carvalho, L.; Santos Silva, M.; Manich, A. Garment Abrasion Strength Evaluation: A Comparative Methods Study. Int. J. Cloth. Sci. Tech. 2007, 19, 194-203. 
(41) de Castellar, M.D.; Saurí, R.M.; Martí, M.; Manich, A. Further Progress on the Abrasion Kinetic Modelling of Woven Fabrics Using the Martindale Abrasion Tester. J. Text. Inst. 2004, 95, 369-379.

(42) Vaswani, S.; Koskinen, J.; Hess, D.W. Surface Modification of Paper and Cellulose by Plasma-Assisted Deposition of Fluorocarbon Films. Surf. Coat. Technol. 2005, 195, 121-129.

(43) Bedane, A.H.; Eić, M.; Farmahini-Farahani M.; Xiao, H. Theoretical Modeling of Water Vapor Transport in Cellulose-Based Materials. Cellulose 2016, 23, 1537-1552.

(44) Cohen, N.; Dotan, A.; Dodiuk, H.; Kenig, S. Superhydrophobic Coatings and Their Durability. Mater. Manuf. Processes 2016, 31, 1143-1155.

(45) Rios, P.F.; Dodiuk, H.; Kenig, S.; McCarthy, S.; Dotan, A. Durable Ultra-Hydrophobic Surfaces for Self-Cleaning Applications. Polym. Adv. Technol. 2008, 19, 1684-1691. 


\section{FIGURES}
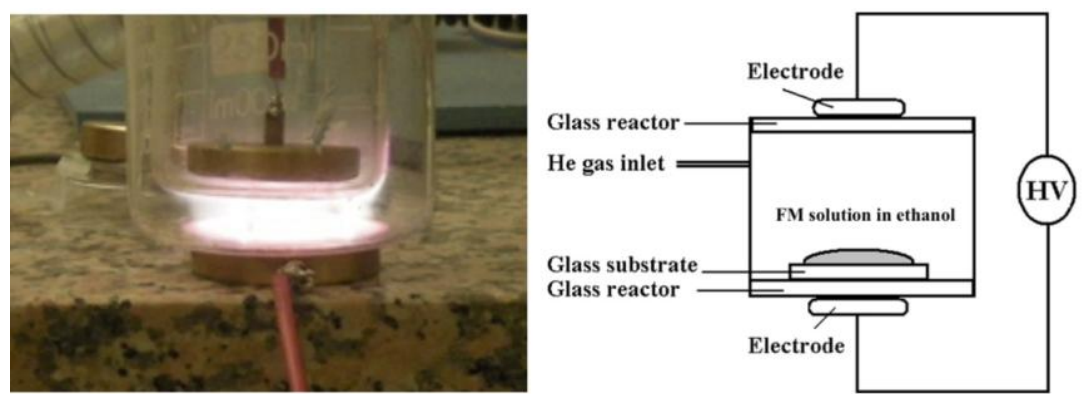

Figure 1. Glass reactor cell (left) and liquid phase plasma polymerization scheme (right). 

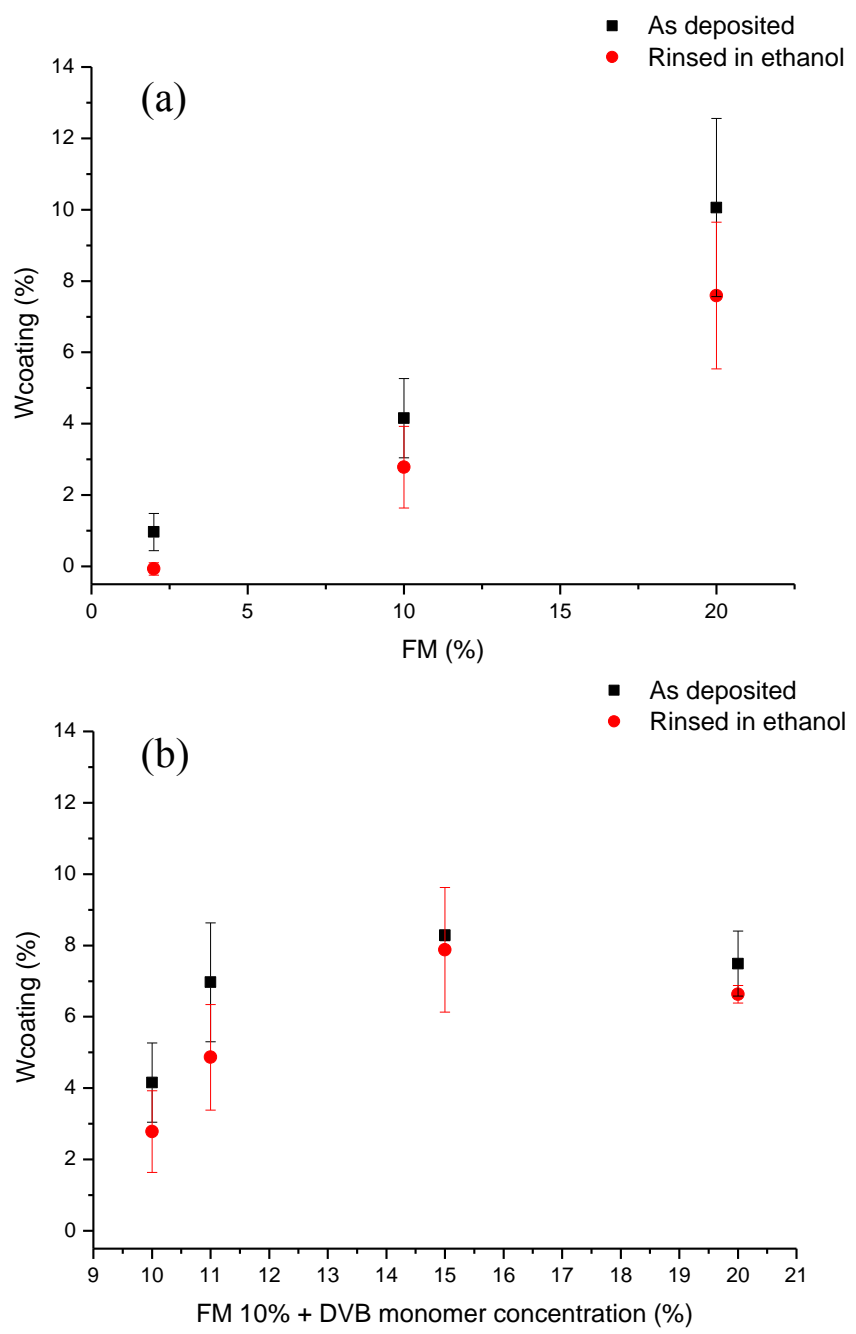

Figure 2. Amount of polymer on cotton substrates (Wcoating), as deposited and after rinsing in ethanol, (a) as a function of fluorinated monomer (FM) concentration and (b) treated with 10\% of fluorinated monomer and copolymerized with hydrophobic divinylbenzene (DVB) at different concentrations $(1 \%, 5 \%$ and $10 \%)$. 

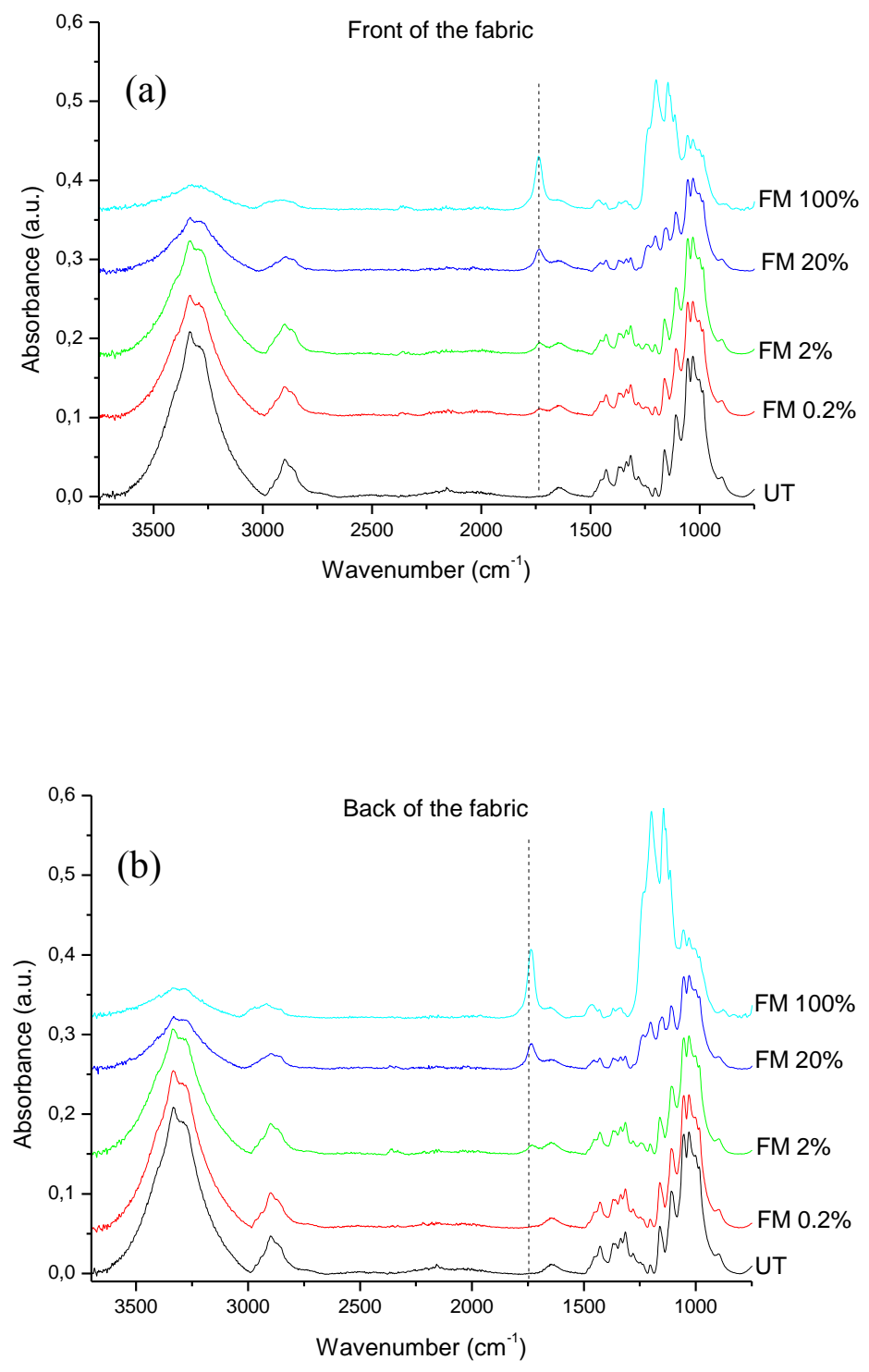

Figure 3. FTIR-ATR spectra of untreated cotton (UT) and plasma polymerized coatings at different concentrations of fluorinated monomer (FM) in ethanol. (a) Front of the fabric (direct exposure to plasma) and (b) back of the fabric. 


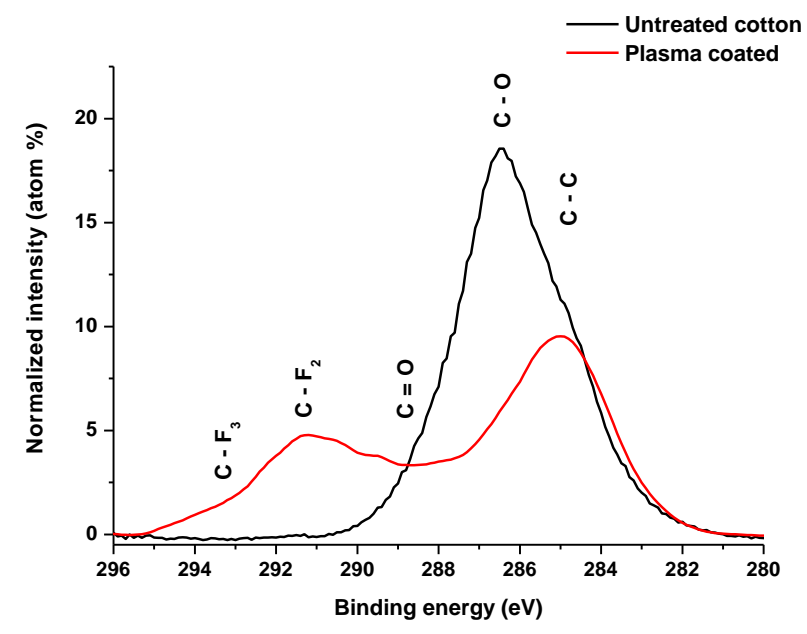

Figure 4. XPS high-resolution $C_{1 s}$ spectra of untreated and plasma fluorinated coatings (concentration of fluorinated monomer $20 \mathrm{wt} \%$ ). 

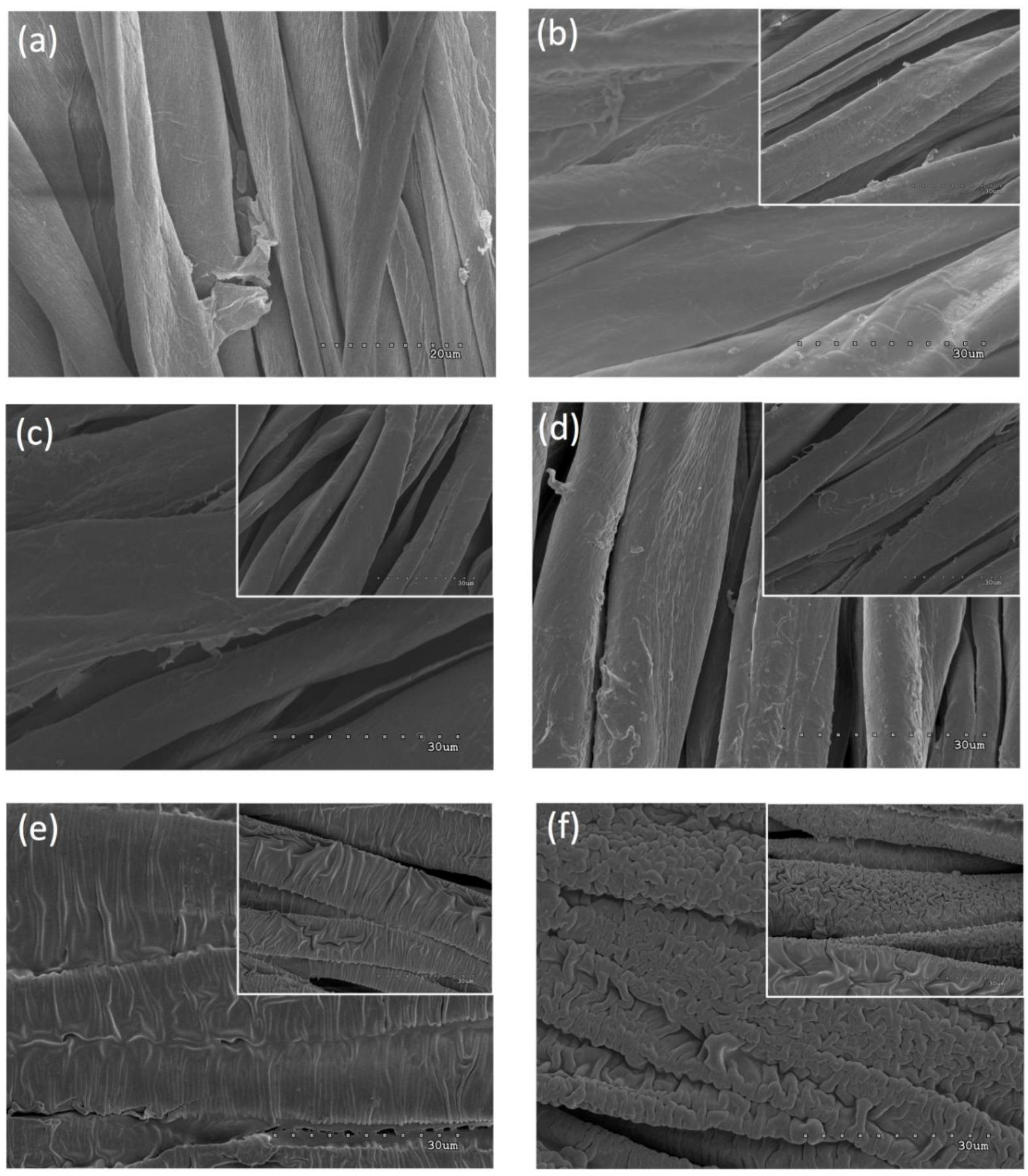

Figure 5. SEM images of (a) untreated cotton; (b) EtOH treated cotton and cotton plasma treated with different FM concentrations: (c) $0.2 \%$; (d) 2\%; (e) and (f) 20\% (inset: back of the fabric). 

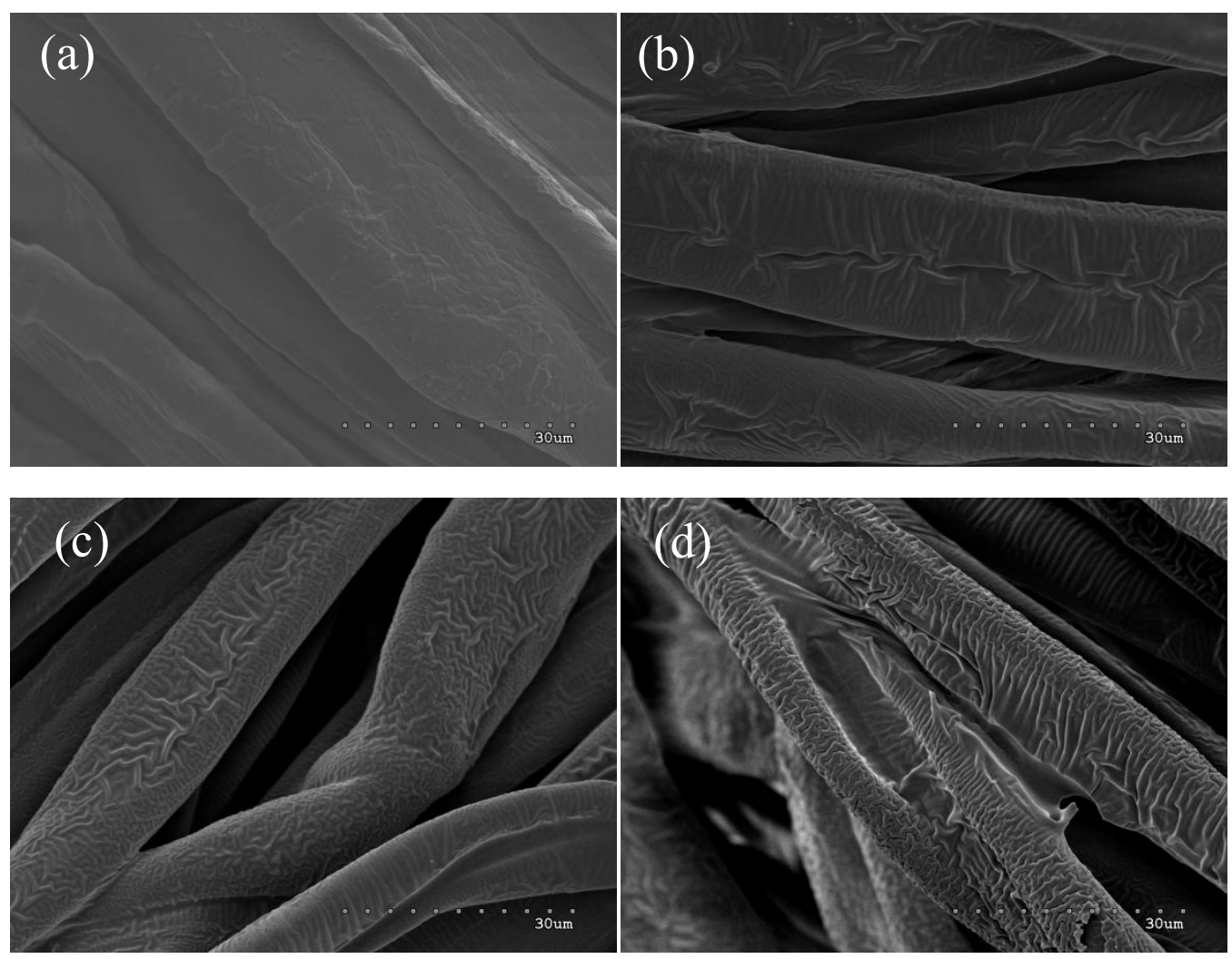

Figure 6. SEM images of plasma treated cotton fabrics with different FM concentrations and subsequently rinsed in ethanol for at least 24 hours: (a) 2\%; (b) 10\%; (c) and (d) 20\%. 


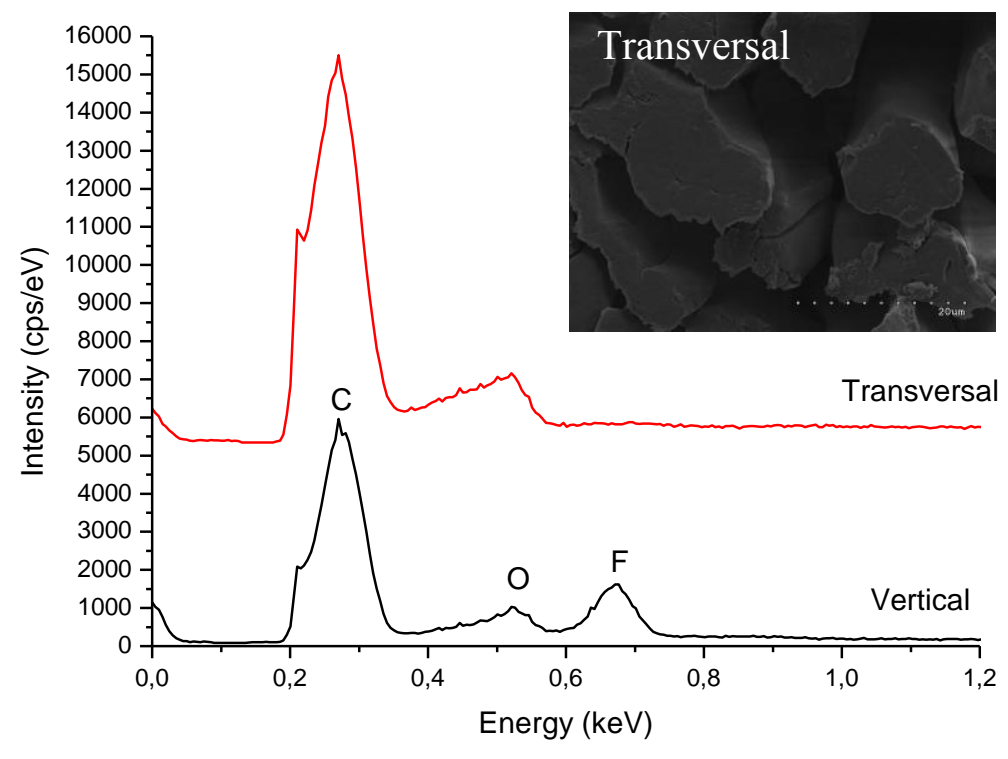

Figure 7. EDX spectra corresponding to the upper part (vertical) and a transversal section of plasma coated cotton fabrics. (inset: SEM image of a transversal zone measured). 


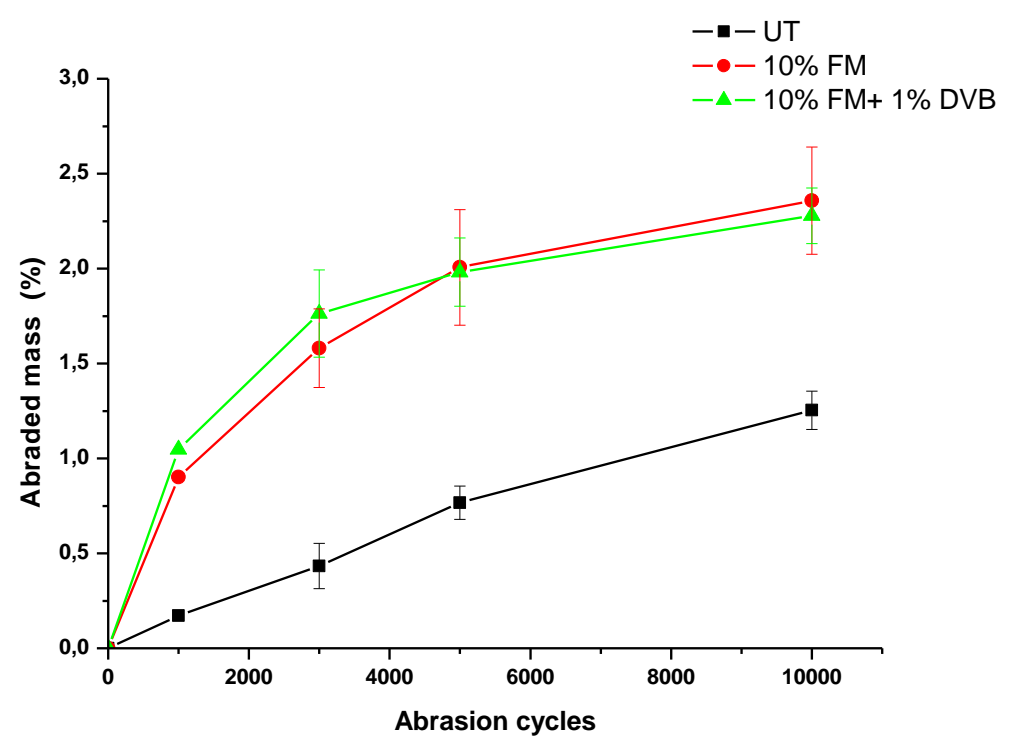

Figure 8. Abraded mass (\%) as a function of abrasion cycles for untreated (UT) and plasma treated cotton fabrics with fluorinated monomer $(10 \% \mathrm{FM})$ and with the addition of a crosslinking agent $(10 \% \mathrm{FM}+1 \% \mathrm{DVB})$. 

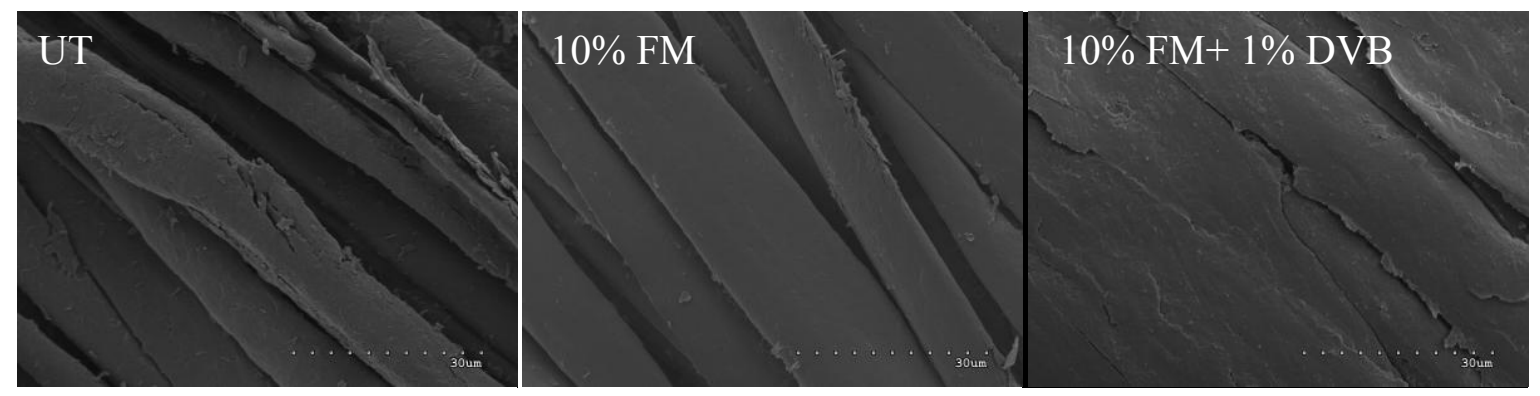

Figure 9. SEM images after 10000 abrasion test cycles for untreated (UT) and plasma treated cotton fabrics with fluorinated monomer $(10 \% \mathrm{FM})$ and with the addition of a crosslinking agent $(10 \% \mathrm{FM}+1 \% \mathrm{DVB})$. 


\section{TABLES}

Table 1. Amount of polymer deposited and percentage of crosslinked polymer present in the plasma coated cotton substrates.

\begin{tabular}{|ccc|}
\hline $\begin{array}{c}\text { Monomer concentration } \\
(\%)\end{array}$ & $\begin{array}{c}\text { Amount of polymer } \\
\text { deposited }(\%)\end{array}$ & Crosslinked polymer (\%) \\
\hline $2 \% \mathrm{FM}$ & $1.0 \pm 0.5$ & $71.8 \pm 55.5$ \\
\hline $10 \% \mathrm{FM}$ & $4.2 \pm 1.1$ & $76.7 \pm 5.2$ \\
\hline $10 \% \mathrm{FM}+1 \% \mathrm{DVB}$ & $7.0 \pm 1.7$ & $73.9 \pm 2.2$ \\
\hline $10 \% \mathrm{FM}+5 \% \mathrm{DVB}$ & $8.3 \pm 0.2$ & $91.5 \pm 8.1$ \\
\hline $10 \% \mathrm{FM}+10 \% \mathrm{DVB}$ & $7.5 \pm 0.9$ & $76.7 \pm 0.1$ \\
\hline $20 \% \mathrm{FM}$ & $10.1 \pm 2.5$ & \\
\hline
\end{tabular}


Table 2. Elemental composition (\%) at the surface determined by XPS.

\begin{tabular}{ccccc}
\hline Sample & $\begin{array}{c}\mathrm{C}_{1 \mathrm{~s}} \\
(\%)\end{array}$ & $\mathrm{N}_{1 \mathrm{~s}}(\%)$ & $\begin{array}{c}\mathrm{O}_{1 \mathrm{~s}} \\
(\%)\end{array}$ & $\begin{array}{c}\mathrm{F}_{1 \mathrm{~s}} \\
(\%)\end{array}$ \\
\hline $\begin{array}{c}\text { Untreated } \\
\text { cotton }\end{array}$ & 63.3 & 0.5 & 36.2 & - \\
\hline $\begin{array}{c}\text { Cotton coated } \\
\text { with 20\% FM }\end{array}$ & 53.8 & - & 8.9 & 37.3 \\
\hline FM theoretical & 42.2 & - & 6.1 & 51.5 \\
composition & & & & \\
\hline \hline
\end{tabular}


Table 3. Wetting time measurement.

\begin{tabular}{|ccc|}
\hline Composition & $\begin{array}{c}\text { Wetting time } \\
\text { Front of the fabric }\end{array}$ & Wetting time \\
& $0 \mathrm{~s}$ & $0 \mathrm{~s}$ \\
\hline Untreated cotton & $10 \mathrm{~s}$ & $2 \mathrm{~s}$ \\
\hline Ethanol & $50 \mathrm{~s}$ & $2 \mathrm{~s}$ \\
\hline $0.2 \% \mathrm{FM}$ & $>60 \mathrm{~min}$ & $>60 \mathrm{~min}$ \\
\hline $2 \% \mathrm{FM}$ & $>60 \mathrm{~min}$ & $>60 \mathrm{~min}$ \\
\hline $20 \% \mathrm{FM}$ & $>60 \mathrm{~min}$ & \\
\hline $100 \% \mathrm{FM}$ & & $>60 \mathrm{~min}$ \\
\hline
\end{tabular}


Table 4. Equilibrium moisture content (\%) of plasma coated cotton fabrics conditioned at $24^{\circ} \mathrm{C}$ and R.H $67 \%$.

\begin{tabular}{|cc|}
\hline $\begin{array}{c}\text { Fluorinated Monomer } \\
\text { concentration }(\%)\end{array}$ & Moisture content $(\%)$ \\
\hline Untreated & $6.45 \pm 0.04$ \\
\hline $2 \% \mathrm{FM}$ & $6.27 \pm 0.01$ \\
\hline $10 \% \mathrm{FM}$ & $6.35 \pm 0.1$ \\
\hline $20 \% \mathrm{FM}$ & $5.99 \pm 0.25$ \\
\hline
\end{tabular}


TABLE OF CONTENTS
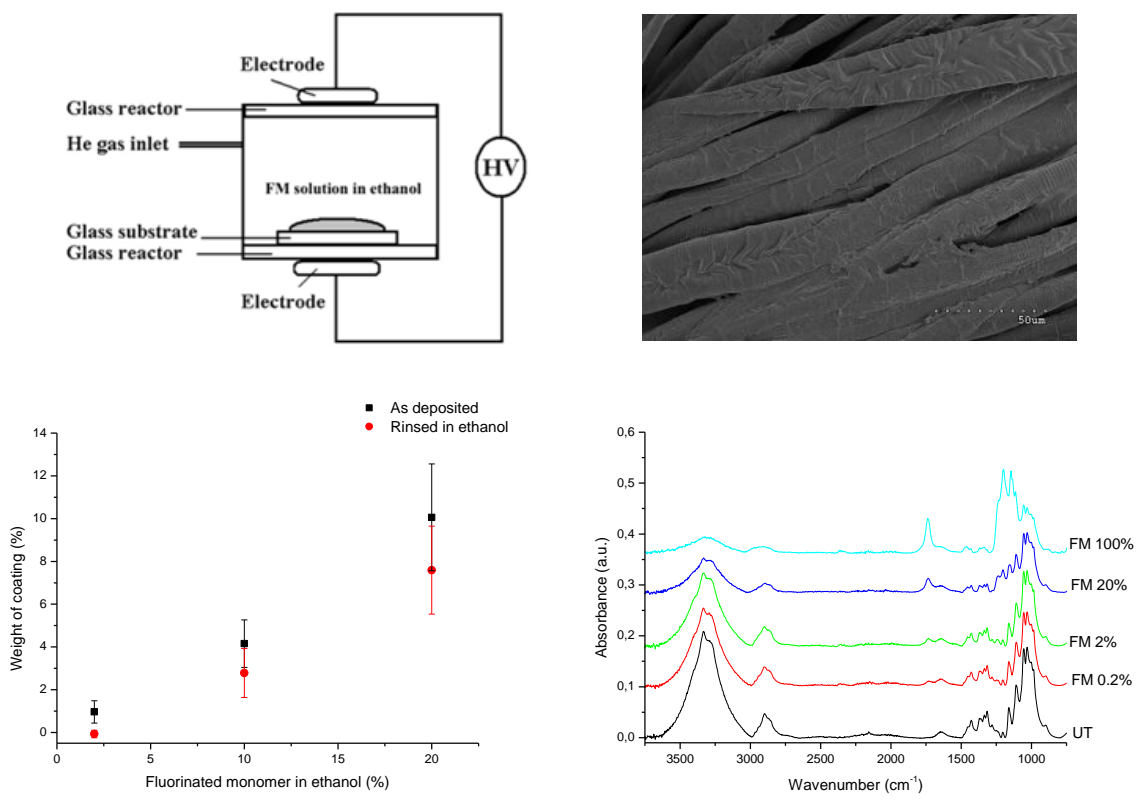